\title{
Gamma Knife versus Frameless Linear Accelerator Based Stereotactic Radiosurgery for Brain Metastases: Clinical Outcomes and Factors Associated with Local Failure and Radiation Necrosis
}

\section{Gregory S. Alexander}

University of Maryland Medical Center

Jill S. Remick

Emory University Winship Cancer Institute

Emily S. Kowalski

University of Maryland School of Medicine

Kai Sun

University of Maryland School of Medicine

Yannick Poirer

University of Maryland School of Medicine

\section{Stewart Becker}

University of Maryland School of Medicine Naru Lamichhane

University of Maryland School of Medicine Howard Eisenberg

University of Maryland School of Medicine

Robert G. Slawson

University of Maryland School of Medicine

\section{Graeme F Woodworth}

University of Maryland School of Medicine

\section{William F. Regine}

University of Maryland School of Medicine

Mark V Mishra ( $\triangle$ mishramv@gmail.com )

University of Maryland School of Medicine

https://orcid.org/0000-0002-2588-1575

\section{Research}

Keywords: SRS, Brain metastases, Radiation Necrosis, Gamma Knife, Linac 
Posted Date: September 15th, 2021

DOl: https://doi.org/10.21203/rs.3.rs-885725/v1

License: (c) (i) This work is licensed under a Creative Commons Attribution 4.0 International License. Read Full License 


\section{Abstract}

\section{Background}

Single-fraction stereotactic radiosurgery (SF-SRS) for the treatment of brain metastases can be delivered with either a Gamma-Knife platform (GK-SRS) or with a frameless linear accelerator (LA-SRS) which vary based on patterns of prescribing, patient setup and radiation delivery. Whether these differences affect clinical outcomes is unknown.

\section{Methods}

Patients treated for metastatic brain cancer treated with SF-SRS from 2014-2020 were retrospectively reviewed and clinical outcomes were recorded on a per lesion basis. Covariates between groups were compared using a Chi-square analysis for dichotomous variables and t-test for continuous variables. Median follow up was calculated using the reverse Kaplan Meier (KM) method. Primary endpoints of local failure (LF) and symptomatic radiation necrosis (RN) were estimated using the KM method with salvage WBRT used as a censoring event. Outcome estimates were compared using the log-rank test. Multivariate analysis (MVA) and Cox proportional hazards modeling were used for statistical analyses. Propensity score (PS) adjustments were used to reduce the effects confounding variables.

Results

Overall, 119 patients with 287 lesions were included for analysis which included 57 patients (127 lesions) treated with LA-SRS compared to 62 patients (160 lesions) treated with GK-SRS. On both multivariate and univariate analysis, there was no statistically significant differences between GK-SRS and LA-SRS for LF, $\mathrm{RN}$, or the combined endpoint of either LF or RN (multivariate p-value $=0.17$ ).

\section{Conclusions}

In our retrospective cohort, we found no statistically significant differences in the incidence of RN or LF in patients treated with GK-SRS when compared to LA-SRS.

Trial Registration: Retrospectively registered

\section{Background}

Stereotactic radiosurgery (SRS) has become increasing utilized for patients with brain metastases in an effort to avoid the risk of neurocognitive decline following whole brain radiation therapy (WBRT).[1] While single fraction SRS is associated with high rates of local control and relatively low rates of toxicity for well selected lesions, local progression or radiation necrosis remain risks following treatment, which are becoming increasingly relevant with continued improvements in survival for patients with metastatic disease associated with the development of new targeted/systemic therapies.[2-5] Therefore, the optimal delivery of SRS remains an important clinical consideration. 
The two primary platforms of SRS delivery include either Gamma Knife (GK) or linear-accelerator-based (LA) approach.[6] These two methods differ in patient set up, prescribing patterns, and radiation delivery. The Gamma Knife platform has historically required the placement of a specialized stereotactic head frame to immobilize the patient, although a frameless platform for GK has also been recently developed. $[7,8]$ Using a frame-based approach, treatment planning is performed using a same day MRI and the prescription dose is prescribed to the $50 \%$ isodose line. Multiple Cobalt- 60 sources are directed to a single isocenter to conformally deliver high doses of radiation from a multitude of angles. $[6,9,10]$

Delivery of SRS with a linear-accelerator can also be delivered using a frame-based approach, but is more commonly used to deliver frameless radiosurgery. Radiation is delivered with multiple non-coplanar arcs with a rotating gantry and is generally prescribed to the $80 \%$ isodose line. An MRI is obtained prior to the delivery of treatment and is fused to the treatment planning CT scan for target delineation. Within LA treatment there exists significant clinical practice variations such as the timing of the treatment planning MRI as well as the inclusion or exclusions of planning target volume (PTV) margin. $[6,9,11,12]$

There are no large definitive prospective trials which compare the rate of local control and radiation necrosis between these two different techniques. RTOG 95-08 showed a non-statistically significant difference in local control rates, but given high rates of local control and low rates of toxicity, larger patient cohorts would likely be necessary to determine statistically significant differences in outcomes.[2] Conversely, a multi-institutional retrospective review suggested an association with GK-SRS and slightly higher rates of radiation necrosis with similar when compared to LA-SRS.[12] A phase III randomized trial comparing GK-SRS and LA-SRS has reported outcomes in abstract form only and again reported a slightly increased incidence of radiation necrosis in the GK arm.[13,14]

The objective of this study was to analyze our institutional experience to compare meaningful outcomes of incidence of symptomatic radiation necrosis or local failure between GK-SRS and LA-SRS. A secondary objective was to identify treatment- or clinical- variables which may impact outcomes for both LA-SRS and GK-SRS cohorts.

\section{Methods}

\section{Data Collection}

An IRB approved retrospective review of patients treated with single fraction SRS for brain metastases with either GK-SRS or LA-SRS within an academic center was conducted. Patients were included for analysis if they had at least one follow-up diagnostic MRI one-month following the completion of radiation therapy. Patients with $>5$ lesions treated at a single session were excluded from analysis. Patient characteristics including age, gender, race, performance status, disease site, histology were collected as well as lesion characteristics such as size, location of brain metastasis, prior radiotherapy to the brain, and treatment with concurrent systemic therapy. Local control and radiation necrosis were recorded on a per lesion basis. Local control and grade 2+ radiation necrosis were determined based on clinical assessment, imaging findings, and pathologic reports when available. Grade 2 radiation necrosis 
was defined as imaging findings consistent with radiation necrosis with clinical symptoms requiring intervention with oral dexamethasone.

\section{Treatment planning and delivery}

SRS was performed with either a frame-based cobalt radiosurgery device or with a frameless linear accelerator. When radiation was delivered with a LA, a rigid SRS mask was created at the time of CT simulation. An MRI acquired prior to the day of treatment was then fused to a treatment planning CT. A gross tumor volume (GTV) was contoured using the contrast enhancing tumor on T1 axial MRI. A planning target volume (PTV) margin of 1 millimeters was added at the treating physician's discretion and the prescription dose was prescribed to the $70-85 \%$ isodose line.

When radiation was delivered by a frame-based platform, treatment planning was performed on an MRI obtained on the day of treatment delivery. The prescription dose was prescribed to the $50 \%$ isodose line directly to the GTV without a PTV expansion.

\section{Statistical Analysis}

The primary endpoints of this study were LF and symptomatic RN. Lesions were censored at the date of last follow up, death, or salvage whole brain. LF and RN probability were estimated by the Kaplan-Meier method and compared between groups using the log-rank test. Because there can often be diagnostic uncertainty between these two clinical outcomes, we also analyzed a composite outcome of either LF or RN. Subset analyses of patients undergoing LA-SRS were performed to determine whether the addition of PTV margin or time from acquisition of treatment planning MRI to treatment completion were associated with clinical outcomes. An additional subset analysis of patients undergoing GK-SRS were performed to determine the clinical effect of dose rate. Dose rate was estimated using previously reported methods. $[15,16]$ Propensity score adjustment was performed using inverse probability of GK weighting, adjusting for location of brain metastases, tumor size, prior WBRT, prior SRS and concurrent systemic therapy.

\section{Results}

\section{Patient Population:}

Table 1 summarizes the baseline characteristics on a per lesion as well as per patient basis. Overall, 119 patients with 287 lesions were included for analysis which included 57 patients (127 lesions) treated with LA-SRS compared to 62 patients (160 lesions) treated with GK-SRS. Patients treated with GK-SRS were more likely to be of white race $(p=0.027)$, have a higher performance status $(p=0.008)$, and were more likely to have received prior WBRT $(p=0.002)$. However, patients treated with LA-SRS and GK-SRS did not have statistically significant differences age (62 vs $59 ; p=0.161)$, or non-squamous histology $(87.7 \%$ vs $93.6 \%, p=0.273$ ). On the lesion-based level, patients being treated with GK-SRS were more likely to have received concurrent systemic therapy $(47.5 \%$ vs $11 \%$; $<<0.000)$, have received prior WBRT $(46.9 \%$ vs $15.75 \% ; p<0.001$, but were less likely to receive salvage WBRT (12.6\% vs $25 \% ; p 0.008)$, and had a longer 
time until salvage WBRT (4.7 vs 13.9 months; $\mathrm{p}<0.000$ ). In terms of lesion size, there was no statistically significant differences in percentage of lesions $>2 \mathrm{~cm}$ treated with GK-SRS vs LA-SRS $(14.17 \%$ vs $8.75 \%$; $p$ $=0.147)$.

\section{Treatment Outcomes and Toxicity:}

For the entire cohort the median follow-up was 11 months (15.2 months GK-SRS vs 7.9 months LA-SRS) with median overall survival 15.9 months (16.2 months GK-SRS vs 12.3 months LA-SRS). For the outcome of local failure, there were no statistically significant differences on univariate or multivariate analysis when comparing outcomes for GK-SRS vs LA-SRS. (Figure 1) Both infratentorial location (multivariate adjusted $p$-value 0.04 ) and tumor size $>2 \mathrm{~cm}$ (multivariate adjusted $p$-value $<0.001$ ) were predictive of local failure. Other factors such as prior WBRT, prior SRS, or receipt of concurrent systemic therapy were not significantly associated with local control. (Table 2)

Additionally, for the outcome of radiation necrosis there was no associated differences between GK-SRS vs LA-SRS (Figure 2) on either multivariate or univariate analysis (multivariate adjusted pvalue $=0.44$ ). Only tumor size $\leq 2 \mathrm{~cm}$ was associated with a decreased risk of radiation necrosis on adjusted multivariate analysis (HR $0.22(0.06-0.88) ; p=0.03)$ (Table 3$)$. For the combined composite outcome of either local failure or radiation necrosis, there were no statistically significant differences between GK-SRS vs LA-SRS on univariate (adjusted HR $0.91(0.54-1.51) ; \mathrm{p}=0.70)$ or multivariate analysis (adjusted HR $0.43(0.13-1.145) p=0.17)$. For the composite outcome of either local failure or radiation necrosis only tumor size $\leq 2 \mathrm{~cm}$ was associated with a decreased risk on multivariate analysis (adjusted HR $0.26(0.12-0.55) p<0.001$.) As expected, there were no differences in distant brain failure (DBF) $(p=0.921)$ or overall survival $(O S)(p=0.512)$ between these two patient cohorts (Figure 3$)$.

On subset analysis of lesions treated with LA-SRS (127 lesions) only tumor size $>2 \mathrm{~cm}$ was found to be statistically significant in predicting local failure $(p<0.001)$ or radiation necrosis $(p=0.04)$. Time of treatment planning MRI to treatment was not found to be associated with respect to local failure (HR 1.00 (0.79-1.27); $p=0.97)$ or radiation necrosis (HR $1.11(0.97-1.28) p=0.13)$. The addition of a PTV margin was also not found to correlate with local failure (HR $0.51(0.11-2.33) p=0.39)$ or radiation necrosis (HR $0.45(0.11-1.97) p=0.27)$. Subset analyses of lesions treated with GK-SRS did not find a meaningful association of dose rate with the risk of radiation necrosis or local failure.

\section{Discussion}

We did not find any statistically significant differences between the incidence of radiation necrosis or local failure for patients treated with LA-SRS when compared to GK-SRS, or the composite outcome of either radiation necrosis or local failure. We evaluated a composite outcome of either radiation necrosis or local failure as these two clinical entities can be difficult to distinguish, but are both clinically-relevant. [17-19] 
Taken together, these findings confirm the findings of the subset analysis of RTOG-9508 which demonstrated no statistically significant difference in outcomes in patients treated with GK-SRS or LASRS,[2] but do not confirm previously reported differences in the incidence of radiation necrosis between the two treatment modalities that was previously reported in a retrospective study.[12] The previously reported multi-institutional experience which found an association with increased radiation necrosis in patients treated with GK-SRS differed from ours as they recorded any grade of radiation necrosis, including asymptomatic radiographical diagnosis. As we felt symptomatic radiation necrosis was a more clinically meaningful endpoint, we only reported grade two or higher radiation necrosis which we defined as symptomatic radiation necrosis requiring intervention with oral dexamethasone or greater. Differences in definition of radiation necrosis varies across many studies and may explain the contradictory findings, though differences in patient population or variation in institutional practices could also play a role.[17] For example, our cohort contained both single and multi-isocenter treatments while other reports may have only single isocenter treatments.

We further analyzed the LA-SRS cohort to determine if variations in physician prescribing patterns or other clinical factors may affect patient outcomes. The decision to prescribe to a tumor GTV or PTV was not found to be statistically significant in terms of local control or radiation necrosis. This finding must be interpreted with caution. With LA-SRS, there exists several steps that may introduce set up uncertainty. The treatment planning MRI must be fused to the CT simulation scan. Subtle differences in patient position between these two scans may introduce error in fusion and ultimately target delineation. Furthermore, institutions vary in terms of set up uncertainty and precision of image guidance. Further, at our institution, physicians who prescribe to the GTV, will often expand the GTV by $1 \mathrm{~mm}$ to create a PTV evaluation structure which used to assess steepness of dose fall off. In settings of uncertain patient set up or a significant interval between treatment planning MRI and date of treatment, then a PTV margin should be more strongly considered; however, given that many patients may receive multiple courses of LA-SRS, it is attractive to prescribe to the GTV only if feasible to achieve OAR doses as low as possible. Ongoing protocols NRG BN009 and NRG CC009 do not mandate the addition of PTV margin and leave the decision up to the discretion of the treating physician.

Timing of the treatment planning MRI was also not found to be associated with increased radiation necrosis or decreased local control which also must be interpreted with caution. Previous reports have shown that brain lesions have a mean growth of approximately $0.02 \mathrm{ml} /$ day in one week.[20] If a large enough period of time has elapsed since previous MRI, target delineation could be compromised. To account for this physician decision regarding the addition of margin or increased margin may have accounted for differences in tumor growth when there was a longer interval to treatment from planning MRI. While our analysis did not detect a difference, a longer interval between MRI acquisition and treatment delivery could still impact outcomes or have an influence on target generation.

Additionally, we analyzed the effect of dose rate for lesions treated with GK-SRS. As Gamma Knife delivers radiotherapy via a cobalt-60 source which undergoes spontaneous decay, the rate that does is delivered will vary depending on the age of the radioactive source as well as other factors. Previous 
reports have suggested that dose rate may impact clinical outcomes for both trigeminal neuralgia and vestibular schwannomas.[16,21] As lower dose rates allow for increased sub-lethal DNA damage, lower dose rates could theoretically result in a lower risk of radiation necrosis and higher risk of local failure. Our study likely lacked sufficient power to determine any differences in this outcome. Larger cohorts with well-matched lesion characteristics would be required to elucidate clinical relevance of dose rate in patients undergoing GK-SRS.

\section{Conclusion}

This experience found no difference in clinical outcomes on a per lesion basis whether single fraction SRS was performed with a GK platform or a LINAC platform. Our findings add to existing evidence and suggests that there is unlikely to be significant clinical differences in meaningful patient outcomes such as local control or radiation necrosis between these two modalities. Large prospective studies would be necessary to confirm these retrospective findings, but the power required to detect a statistically significant difference between these two treatment outcomes would likely preclude feasibility of such trials considering high rates of local control and relatively low rates of symptomatic toxicity.

\section{Abbreviations}

SF - Single-fraction

SRS - stereotactic radiosurgery

GK - Gamma-Knife

LA - Frameless linear accelerator stereotactic radiosurgery

KM - Kaplan Meier

LF - Local Failure

RN - Symptomatic Radiation Necrosis

MVA - Multivariate analysis

PS - Propensity score

PTV - planning target volume

GTV - Gross tumor volume

WBRT - whole brain radiotherapy

DBF - distant brain failure 
HR - Hazard ratio

\section{Declarations}

Ethics approval and consent to participate: This study was approved by the institutional review board (IRB) of the University of Maryland, Baltimore.

Consent for publication: Not applicable

Availability of data and materials: All data generated or analyzed during this study are included in this published article.

Competing interests: MVM reports receiving an honorarium from Varian, outside of the scope of the present work.

Funding: Author contributions All authors contributed to the writing and interpretation of the results of this study. KS was in charge of the statistical analysis. All authors read and approved the final manuscript.

Acknowledgments: Not applicable

\section{References}

1. Stereotactic radiosurgery alone for multiple brain metastases? A review of clinical and technical issues | Neuro-Oncology | Oxford Academic [Internet]. [cited 2020 Nov 5]. Available from: https://academic.oup.com/neuro-oncology/article/19/suppl_2/ii2/3097609

2. Andrews DW, Scott CB, Sperduto PW, Flanders AE, Gaspar LE, Schell MC, et al. Whole brain radiation therapy with or without stereotactic radiosurgery boost for patients with one to three brain metastases: phase III results of the RTOG 9508 randomised trial. Lancet. 2004;363:1665-72.

3. Auchter RM, Lamond JP, Alexander E, Buatti JM, Chappell R, Friedman WA, et al. A multiinstitutional outcome and prognostic factor analysis of radiosurgery for resectable single brain metastasis. Int $\mathrm{J}$ Radiat Oncol Biol Phys. 1996;35:27-35.

4. Kondziolka D, Patel A, Lunsford LD, Kassam A, Flickinger JC. Stereotactic radiosurgery plus whole brain radiotherapy versus radiotherapy alone for patients with multiple brain metastases. Int J Radiat Oncol Biol Phys. 1999;45:427-34.

5. Sanghavi SN, Miranpuri SS, Chappell R, Buatti JM, Sneed PK, Suh JH, et al. Radiosurgery for patients with brain metastases: a multi-institutional analysis, stratified by the RTOG recursive partitioning analysis method. Int J Radiat Oncol Biol Phys. 2001;51:426-34. 
6. Park HS, Wang EH, Rutter CE, Corso CD, Chiang VL, Yu JB. Changing practice patterns of Gamma Knife versus linear accelerator-based stereotactic radiosurgery for brain metastases in the US. Journal of Neurosurgery. American Association of Neurological Surgeons; 2016;124:1018-24.

7. Chung H-T, Park W-Y, Kim TH, Kim YK, Chun KJ. Assessment of the accuracy and stability of frameless gamma knife radiosurgery. Journal of Applied Clinical Medical Physics. 2018;19:148-54.

8. Vulpe H, Save AV, Xu Y, Elliston CD, Garrett MD, Wu C-C, et al. Frameless Stereotactic Radiosurgery on the Gamma Knife Icon: Early Experience From 100 Patients. Neurosurgery. Oxford Academic; 2020;86:509-16.

9. Goetsch SJ. Linear Accelerator and Gamma Knife-Based Stereotactic Cranial Radiosurgery: Challenges and Successes of Existing Quality Assurance Guidelines and Paradigms. International Journal of Radiation Oncology*Biology*Physics. 2008;71:S118-21.

10. Goodman M. Gamma Knife Radiosurgery: Current Status and Review. Southern Medical Journal. 1990;83:551-4.

11. Kowalski ES, Remick JS, Sun K, Alexander GS, Khairnar R, Morse E, et al. Immune checkpoint inhibition in patients treated with stereotactic radiation for brain metastases. Radiat Oncol [Internet]. 2020 [cited 2020 Nov 5];15. Available from: https://www.ncbi.nlm.nih.gov/pmc/articles/PMC7590444/

12. Sebastian NT, Glenn C, Hughes R, Raval R, Chu J, DiCostanzo D, et al. Linear accelerator-based radiosurgery is associated with lower incidence of radionecrosis compared with gamma knife for treatment of multiple brain metastases. Radiotherapy and Oncology. 2020;147:136-43.

13. Scorsetti M, Navarria P, Ascolese A, Clerici E, Mancosu P, Picozzi P, et al. OS03.4 Gammaknife versus Linac based (EDGE) radiosurgery (SRS) for patients with limited brain metastases (BMS) from different solid tumor: a phase III randomized trial. Neuro Oncol. Oxford Academic; 2017;19:iii5-6.

14. Navarria P, Clerici E, Carta G, Attuati L, Picozzi P, Franzese C, et al. Randomized Phase III Trial Comparing Gamma Knife and Linac Based (EDGE) Approaches for Brain Metastases Radiosurgery: Results from the Gadget Trial. International Journal of Radiation Oncology*Biology*Physics. 2018;102:S143-4.

15. Paddick I, Hopewell JW, Klinge T, Graffeo CS, Pollock BE, Sneed PK. Letter: Treatment Outcomes and Dose Rate Effects Following Gamma Knife Stereotactic Radiosurgery for Vestibular Schwannomas. Neurosurgery. Oxford Academic; 2020;86:E407-9.

16. Smith DR, Saadatmand HJ, Wu C-C, Black PJ, Wuu Y-R, Lesser J, et al. Treatment Outcomes and Dose Rate Effects Following Gamma Knife Stereotactic Radiosurgery for Vestibular Schwannomas. Neurosurgery. 2019;85:E1084-94. 
17. Vellayappan B, Tan CL, Yong C, Khor LK, Koh WY, Yeo TT, et al. Diagnosis and Management of Radiation Necrosis in Patients With Brain Metastases. Front Oncol [Internet]. 2018 [cited 2020 Nov 5];8. Available from: https://www.ncbi.nlm.nih.gov/pmc/articles/PMC6172328/

18. Buboltz JB, Tadi P. Hyperbaric Treatment Of Brain Radiation Necrosis. StatPearls [Internet]. Treasure Island (FL): StatPearls Publishing; 2020 [cited 2020 Nov 5]. Available from:

http://www.ncbi.nlm.nih.gov/books/NBK431083/

19. Ricci PE, Karis JP, Heiserman JE, Fram EK, Bice AN, Drayer BP. Differentiating recurrent tumor from radiation necrosis: time for re-evaluation of positron emission tomography? American Journal of Neuroradiology. American Journal of Neuroradiology; 1998;19:407-13.

20. Garcia MA, Anwar M, Yu Y, Duriseti S, Merritt B, Nakamura J, et al. Brain metastasis growth on preradiosurgical magnetic resonance imaging. Pract Radiat Oncol. 2018;8:e369-76.

21. Lee JYK, Sandhu S, Miller D, Solberg T, Dorsey JF, Alonso-Basanta M. Higher dose rate Gamma Knife radiosurgery may provide earlier and longer-lasting pain relief for patients with trigeminal neuralgia. $J$ Neurosurg. 2015;123:961-8.

\section{Tables}

Table 1a. Patient level characteristics. 


\begin{tabular}{lllll} 
Variable & Overall & LINAC & GK & p-value \\
\hline Age & $59(54,67)$ & $62(56,66)$ & $59(52,67)$ & 0.16 \\
\hline Gender & & & & 0.10 \\
\hline Male & $49(41.18 \%)$ & $19(33.33 \%)$ & $30(48.39 \%)$ & \\
\hline Female & $70(58.82 \%)$ & $38(66.67 \%)$ & $32(51.61 \%)$ & \\
\hline Race & & & & 0.03 \\
\hline White & $81(68.07 \%)$ & $32(56.14 \%)$ & $49(79.03 \%)$ & \\
\hline Black & $30(25.21 \%)$ & $20(35.09 \%)$ & $10(16.13 \%)$ & \\
\hline Other & $8(6.72 \%)$ & $5(8.77 \%)$ & $3(4.84 \%)$ & \\
\hline KPS & & & & $<0.001$ \\
\hline$<80$ & $20(16.81 \%)$ & $15(26.32 \%)$ & $5(8.06 \%)$ & \\
\hline $80-100$ & $99(83.19 \%)$ & $42(73.68 \%)$ & $57(91.94 \%)$ & \\
\hline Primary Site of Disease & & & & 0.52 \\
\hline Lung & $73(61.34 \%)$ & $35(61.4 \%)$ & $38(61.29 \%)$ & \\
\hline Breast & $15(12.61 \%)$ & $9(15.79 \%)$ & $6(9.68 \%)$ & \\
\hline Other & $31(26.05 \%)$ & $13(22.81 \%)$ & $18(29.03 \%)$ & \\
\hline & & & & \\
\hline
\end{tabular}

Table 1b. Lesion level characteristics. 


\begin{tabular}{|c|c|c|c|c|}
\hline Variable & Overall & LINAC & GK & $p$-value \\
\hline Metastasis Size & & & & 0.15 \\
\hline$\leq 2 \mathrm{~cm}$ & $255(88.85 \%)$ & 109(85.83\%) & $146(91.25 \%)$ & \\
\hline$>2 \mathrm{~cm}$ & $32(11.15 \%)$ & $18(14.17 \%)$ & $14(8.75 \%)$ & \\
\hline Location of Brain Metastasis & & & & 0.03 \\
\hline Supratentorial & $218(75.96 \%)$ & $90(70.87 \%)$ & $128(80 \%)$ & \\
\hline Infratentorial & $60(20.91 \%)$ & $35(27.56 \%)$ & $25(15.63 \%)$ & \\
\hline Brainstem & $9(3.14 \%)$ & $2(1.57 \%)$ & $7(4.38 \%)$ & \\
\hline Concurrent Systemic therapy & & & & $<0.001$ \\
\hline No & 197(68.64\%) & 113(88.98\%) & $84(52.5 \%)$ & \\
\hline Yes & $90(31.36 \%)$ & $14(11.02 \%)$ & $76(47.5 \%)$ & \\
\hline Prior WBRT & & & & $<0.001$ \\
\hline No & $192(66.9 \%)$ & $107(84.25 \%)$ & $85(53.13 \%)$ & \\
\hline Yes & $95(33.1 \%)$ & $20(15.75 \%)$ & $75(46.88 \%)$ & \\
\hline Prior SRS & & & & 0.89 \\
\hline No & $209(72.82 \%)$ & $93(73.23 \%)$ & $116(72.5 \%)$ & \\
\hline Yes & $78(27.18 \%)$ & $34(26.77 \%)$ & $44(27.5 \%)$ & \\
\hline Salvage WBRT & & & & $<0.001$ \\
\hline No & $231(80.49 \%)$ & $111(87.4 \%)$ & $120(75 \%)$ & \\
\hline Yes & $56(19.51 \%)$ & $16(12.6 \%)$ & $40(25 \%)$ & \\
\hline Time to Salvage WBRT & $8.4(5,15.2)$ & $4.7(1.9,7.8)$ & $13.9(6.2,16.5)$ & $<0.001$ \\
\hline
\end{tabular}

WBRT (whole brain radiation therapy)

* Propensity score adjustment performed using inverse probability of GK weighting, adjusting for Location of brain met, tumor size, prior WBRT, Prior brain SRS, and concurrent systemic therapy.

Table 2. Univariate and Multivariate Analysis for Local Failure. 


\begin{tabular}{|c|c|c|c|c|c|}
\hline \multicolumn{6}{|l|}{ Covariate } \\
\hline \multicolumn{3}{|l|}{ Univariate } & \multicolumn{3}{|c|}{$\begin{array}{l}\text { Unadjusted HR }(95 \% \mathrm{Cl}) \quad \begin{array}{l}\text { Unadjusted p-value } \\
\text { Adjusted HR }(95 \% \mathrm{Cl}) \quad \text { Adjusted p-value }\end{array}\end{array}$} \\
\hline \multirow[t]{3}{*}{$\begin{array}{l}\text { Location of brain } \\
\text { metastasis }\end{array}$} & \multicolumn{2}{|c|}{ Infratentorial } & \multicolumn{2}{|c|}{$\begin{array}{l}0.45(0.11-1.95) \\
0.34(0.10-1.21)\end{array}$} & $0.10^{0.29}$ \\
\hline & \multicolumn{2}{|c|}{ Brainstem } & \multicolumn{2}{|c|}{$\begin{array}{l}1.56(0.21-11.73) \\
2.90(0.96-8.77)\end{array}$} & $0.06^{0.66}$ \\
\hline & \multicolumn{2}{|c|}{ Supratentorial } & \multicolumn{2}{|c|}{ reference } & \\
\hline \multicolumn{3}{|l|}{ Tumor size $\leq 2 \mathrm{~cm}$} & \multicolumn{2}{|c|}{$\begin{array}{l}0.34(0.13-0.94) \\
0.37(0.17-0.78)\end{array}$} & 0.01 \\
\hline \multicolumn{3}{|l|}{ GK vs LINAC } & \multicolumn{2}{|c|}{$\begin{array}{l}0.97(0.38-2.46) \\
1.09(0.54-2.22)\end{array}$} & $0.81^{0.95}$ \\
\hline \multicolumn{3}{|c|}{ Concurrent systemic therapy } & \multicolumn{2}{|c|}{$\begin{array}{l}1.34(0.56-3.18) \\
1.08(0.54-2.16)\end{array}$} & $0.83^{0.51}$ \\
\hline \multicolumn{3}{|l|}{ Prior WBRT } & \multicolumn{2}{|c|}{$\begin{array}{l}1.99(0.98-4.04) \\
1.16(0.58-2.30)\end{array}$} & $0.67^{0.06}$ \\
\hline \multicolumn{3}{|l|}{ Prior brain SRS } & \multicolumn{2}{|c|}{$\begin{array}{l}1.78(0.74-4.30) \\
1.86(0.97-3.60)\end{array}$} & $0.06^{0.20}$ \\
\hline \multicolumn{2}{|l|}{ Multivariate } & \multicolumn{2}{|c|}{$\begin{array}{l}\text { Unadjusted HR } \\
(95 \% \mathrm{Cl})\end{array}$} & \multicolumn{2}{|c|}{$\begin{array}{l}\text { Unadjusted p-value Adjusted } \mathrm{H} \\
\mathrm{Cl} \text { ) Adjusted } \mathrm{p} \text {-value }\end{array}$} \\
\hline \multicolumn{2}{|l|}{ GK-vs LINAC } & \multicolumn{2}{|c|}{$0.63(0.18-2.22)$} & $\begin{array}{l}0.47 \\
0.22\end{array}$ & $0.41(0.10-1.72)$ \\
\hline \multicolumn{2}{|l|}{ Tumor size $\leq 2 \mathrm{~cm}$} & \multicolumn{2}{|c|}{$0.29(0.09-0.99)$} & $\begin{array}{l}0.047 \\
0.07\end{array}$ & $0.29(0.08-1.09)$ \\
\hline \multicolumn{2}{|l|}{ Prior WBRT } & \multicolumn{2}{|c|}{$1.20(0.35-4.15)$} & 0.77 & $1.31(0.30-5.76)$ \\
\hline \multirow{3}{*}{$\begin{array}{l}\text { Location of } \\
\text { brain } \\
\text { metastasis }\end{array}$} & Infratentorial & \multicolumn{2}{|c|}{$0.43(0.09-2.09)$} & 0.30 & $0.16(0.03-0.81)$ \\
\hline & Brainstem & \multicolumn{2}{|c|}{$1.73(0.18-17.12)$} & 0.64 & $6.12(1.09-34.40)$ \\
\hline & Supratentorial & & & & \\
\hline
\end{tabular}

WBRT (whole brain radiation therapy)

* Propensity score adjustment performed using inverse probability of GK weighting, adjusting for Location of brain met, tumor size, prior WBRT, Prior brain SRS, and concurrent systemic therapy. 
Table 3. Univariate and Multivariate Analysis for Radiation Necrosis

\begin{tabular}{|c|c|c|c|c|c|}
\hline \multicolumn{6}{|l|}{ Covariate } \\
\hline \multicolumn{3}{|l|}{ Univariate } & \multicolumn{3}{|c|}{$\begin{array}{l}\text { Unadjusted HR }(95 \% \mathrm{Cl}) \quad \text { Unadjusted p-value } \\
\text { Adjusted HR }(95 \% \mathrm{Cl}) \quad \text { Adjusted p-value }\end{array}$} \\
\hline \multirow[t]{3}{*}{$\begin{array}{l}\text { Location of brain } \\
\text { metastasis }\end{array}$} & \multicolumn{2}{|c|}{ infratentorial } & \multicolumn{2}{|c|}{$\begin{array}{c}0.38(0.09-1.63) \\
0.30(0.09-1.02)\end{array}$} & $0.053^{0.19}$ \\
\hline & \multicolumn{2}{|c|}{ brainstem } & \multicolumn{2}{|c|}{$\begin{array}{c}1.48(0.20-11.04) \\
1.37(0.32-5.86)\end{array}$} & $0.67^{0.70}$ \\
\hline & \multicolumn{2}{|c|}{ supratentorial } & \multicolumn{2}{|c|}{ reference } & \\
\hline \multicolumn{3}{|l|}{ Tumor size $\leq 2 \mathrm{~cm}$} & \multicolumn{2}{|c|}{$\begin{array}{l}0.36(0.13-0.96) \\
0.50(0.23-1.10)\end{array}$} & $0.09^{0.04}$ \\
\hline \multicolumn{3}{|l|}{ GK vs LINAC } & \multicolumn{2}{|c|}{$\begin{array}{l}0.75(0.31-1.82) \\
0.76(0.38-1.54)\end{array}$} & 0.45 \\
\hline \multicolumn{3}{|c|}{ Concurrent systemic therapy } & \multicolumn{2}{|c|}{$\begin{array}{l}0.60(0.25-1.47) \\
0.73(0.36-1.50)\end{array}$} & $0.39^{0.27}$ \\
\hline \multicolumn{3}{|l|}{ Prior WBRT } & \multicolumn{2}{|c|}{$\begin{array}{l}2.21(0.97-5.01) \\
1.98(1.05-3.74)\end{array}$} & 0.04 \\
\hline \multicolumn{3}{|l|}{ Prior brain SRS } & \multicolumn{2}{|c|}{$\begin{array}{l}0.82(0.30-2.19) \\
0.78(0.36-1.65)\end{array}$} & $0.51^{0.69}$ \\
\hline \multicolumn{2}{|l|}{ Multivariate } & \multicolumn{2}{|c|}{$\begin{array}{l}\text { Unadjusted HR } \\
(95 \% \mathrm{Cl})\end{array}$} & $\begin{array}{l}\text { Unadjusted p-value } \\
\mathrm{Cl} \text { ) Adjusted p-value }\end{array}$ & $\begin{array}{l}\text {-value Adjusted HR (95\% } \\
\text { p-value }\end{array}$ \\
\hline \multicolumn{2}{|l|}{ GK-vs LINAC } & \multicolumn{2}{|c|}{$0.44(0.11-1.72)$} & $\begin{array}{r}0.24 \\
0.44\end{array}$ & $0.54(0.11-2.59)$ \\
\hline \multicolumn{2}{|l|}{ Tumor size $\leq 2 \mathrm{~cm}$} & \multicolumn{2}{|c|}{$0.30(0.09-1.07)$} & $\begin{array}{l}0.06 \\
0.03\end{array}$ & $0.22(0.06-0.88)$ \\
\hline \multicolumn{2}{|l|}{ Prior WBRT } & \multicolumn{2}{|c|}{$2.38(0.66-8.62)$} & $\begin{array}{l}0.19 \\
0.54\end{array}$ & $1.55(0.39-6.14)$ \\
\hline \multirow{3}{*}{$\begin{array}{l}\text { Location of } \\
\text { brain } \\
\text { metastasis }\end{array}$} & infratentorial & \multicolumn{2}{|c|}{$0.43(0.09-1.97)$} & $\begin{array}{l}0.28 \\
0.32\end{array}$ & $0.46(0.10-2.12)$ \\
\hline & brainstem & \multicolumn{2}{|c|}{$0.81(0.06-11.03)$} & $\begin{array}{l}0.88 \\
0.15\end{array}$ & $0.22(0.03-1.75)$ \\
\hline & Supratentorial & \multicolumn{2}{|c|}{ reference } & & \\
\hline
\end{tabular}

WBRT (whole brain radiation therapy)

* Propensity score adjustment performed using inverse probability of GK weighting, adjusting for Location of brain met, tumor size, prior WBRT, Prior brain SRS, and concurrent systemic therapy. 
Figures

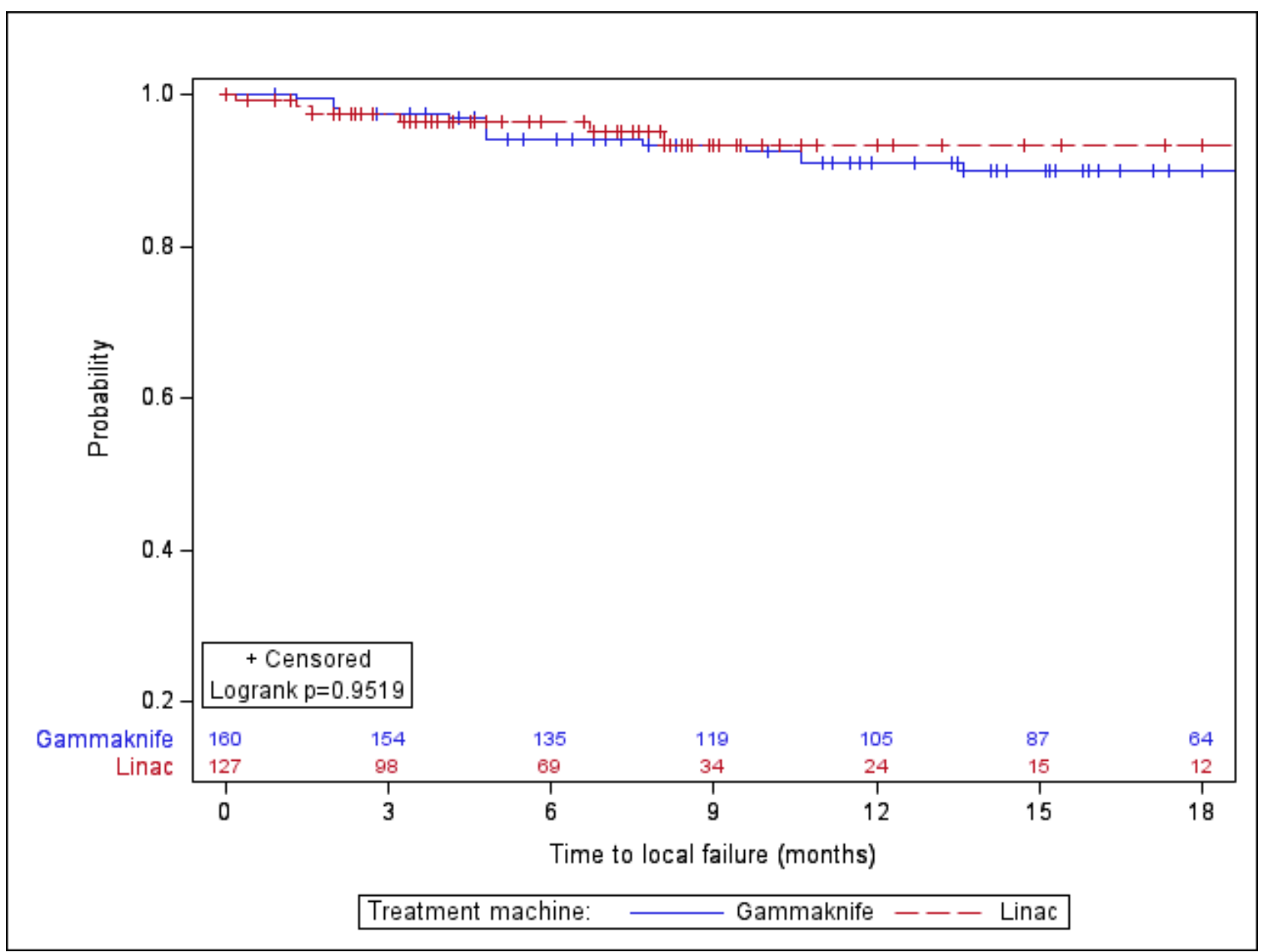

Figure 1

Kaplan Meyer comparison of local failure of lesions treated with Gamma Knife (blue) or Linear accelerator (red) based SRS. 


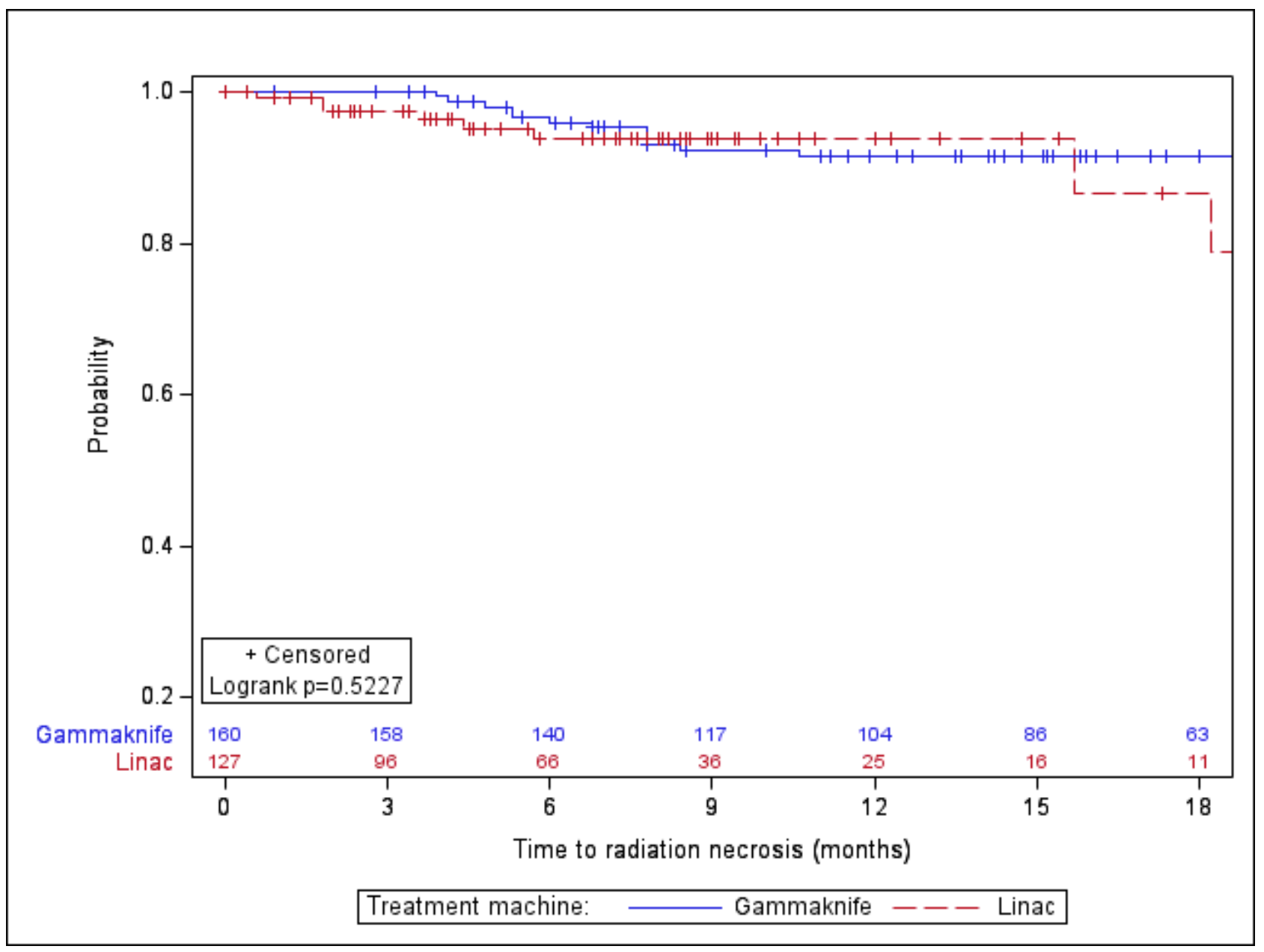

\section{Figure 2}

Kaplan Meyer comparison of symptomatic radiation necrosis from lesions treated with Gamma Knife (blue) or Linear accelerator (red) based SRS. 


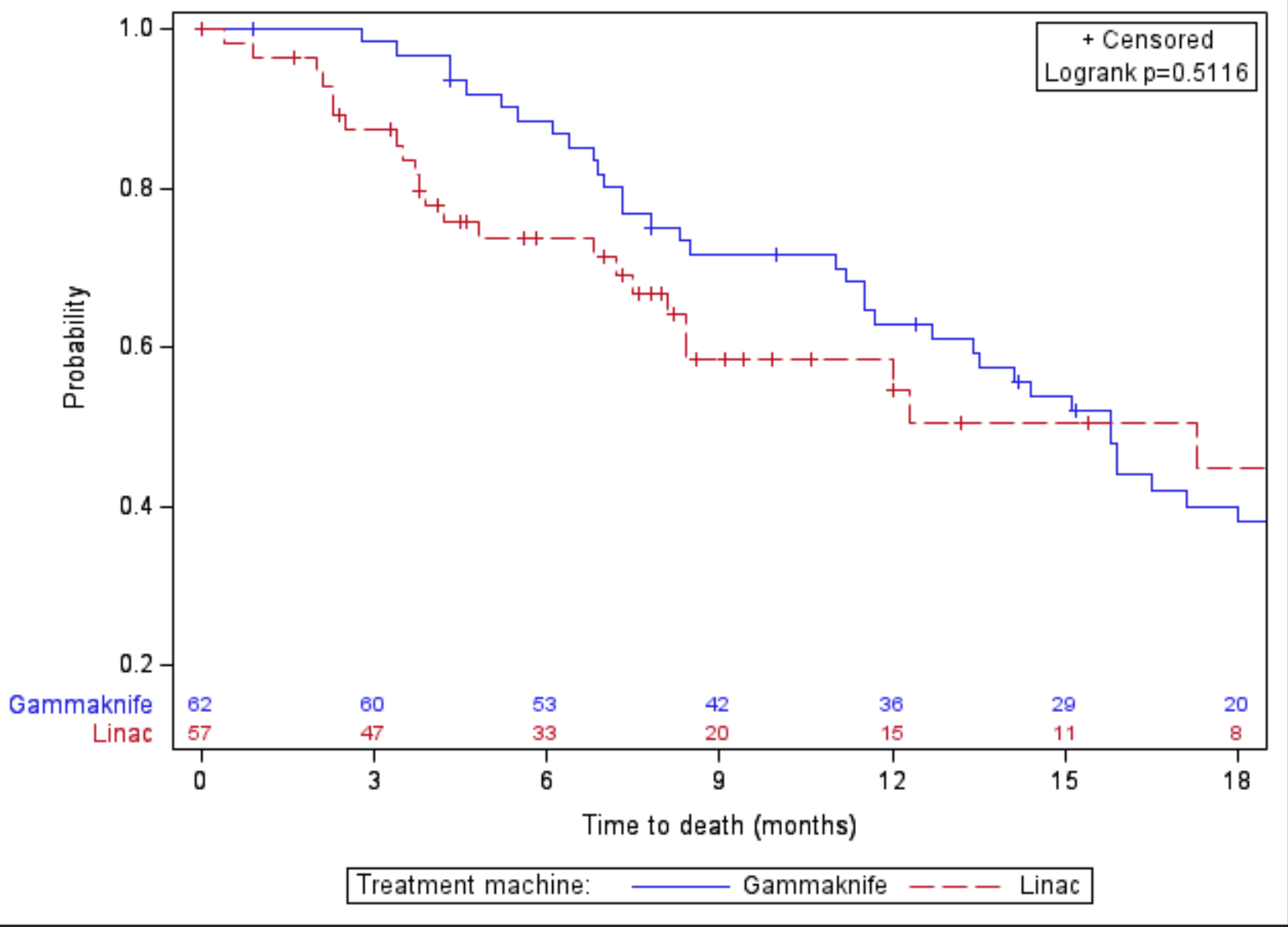

Figure 3

Kaplan Meyer comparison of overall survival for patients treated with Gamma Knife (blue) or Linear accelerator (red) based SRS. Informed Consent Statement: Informed consent was not obtained or sought for this study according to IRB approval/institutional guidelines due to lack of feasibility and minimal/no risk to patients. 